\title{
Gas sensing with gold-decorated vertically aligned carbon nanotubes
}

\author{
Prasantha R. Mudimela ${ }^{1}$, Mattia Scardamaglia ${ }^{2}$, Oriol González-León ${ }^{3}$, \\ Nicolas Reckinger ${ }^{1}$, Rony Snyders ${ }^{2}$, Eduard Llobet ${ }^{3}$, Carla Bittencourt ${ }^{*}$ \\ and Jean-François Colomer ${ }^{1}$
}

\section{Letter}

\section{Address:}

${ }^{1}$ Research group on Carbon Nanostructures (CARBONNAGe), University of Namur, Belgium, ${ }^{2}$ Chimie des Interactions Plasma-Surface (ChIPS), CIRMAP, Research Institute for Materials Science and Engineering, University of Mons, Mons, Belgium and ${ }^{3}$ MINOS-EMaS, Universitat Rovira i Virgili, Tarragona, Spain

Email:

Carla Bittencourt ${ }^{*}$ - carla.bittencourt@umons.ac.be

* Corresponding author

Keywords:

alignment; carbon nanotubes; decoration; gas sensors; metal nanoparticles; thermal CVD

\author{
Beilstein J. Nanotechnol. 2014, 5, 910-918. \\ doi:10.3762/bjnano.5.104 \\ Received: 04 March 2014 \\ Accepted: 08 June 2014 \\ Published: 26 June 2014 \\ Associate Editor: P. Leiderer \\ (C) 2014 Mudimela et al; licensee Beilstein-Institut. \\ License and terms: see end of document.
}

\begin{abstract}
Vertically aligned carbon nanotubes of different lengths $(150,300,500 \mu \mathrm{m})$ synthesized by thermal chemical vapor deposition and decorated with gold nanoparticles were investigated as gas sensitive materials for detecting nitrogen dioxide $\left(\mathrm{NO}_{2}\right)$ at room temperature. Gold nanoparticles of about $6 \mathrm{~nm}$ in diameter were sputtered on the top surface of the carbon nanotube forests to enhance the sensitivity to the pollutant gas. We showed that the sensing response to nitrogen dioxide depends on the nanotube length. The optimum was found to be $300 \mu \mathrm{m}$ for getting the higher response. When the background humidity level was changed from dry to $50 \%$ relative humidity, an increase in the response to $\mathrm{NO}_{2}$ was observed for all the sensors, regardless of the nanotube length.
\end{abstract}

\section{Introduction}

The interest in gas sensing for reaching a widespread, continuous pollution detection and control has been growing steadily in the last decades due to the increasing impact in our environment of human activities. The detection of typical pollutants such as nitrogen dioxide $\left(\mathrm{NO}_{2}\right)$ generated by industrial combustions or by car emissions is critical because of both environmental problems and health consequences for humans. In the last few years, new technologies based on nanomaterials have been developed to fabricate small and inexpensive gas sensors with high sensitivity and able to work at room temperature [1].
Among the possible active materials in gas sensing devices, good candidates are carbon nanotubes (CNTs), thanks to their intrinsic properties such as very large surface area to volume ratio, high electron mobility, physico-chemical stability and high adsorption capability [2-5]. The use of CNTs as gas sensors was first proposed by Kong et al., who showed that a dramatic change in the electrical resistance of an individual single-walled nanotube occurs upon exposure to different gases, including $\mathrm{NO}_{2}$ [5]. Since this first study, gas sensors based on CNT films, i.e., random CNT networks (single- or multi-walled 
nanotubes) were intensively investigated and shown to exhibit, in some particular cases, high sensitivity (even when operated at room temperature), prompt response, short recovery time and reasonable reversibility and stability [2-4,6]. A further advance in the development of CNT gas sensing devices was the use of vertically aligned CNTs (VA-CNTs). In this case the sensing device benefits from the unidirectional electrical charge transport [7], unlike in randomly oriented CNT meshes. Sensors made of aligned CNTs synthesized by plasma enhanced chemical vapour deposition (PECVD), have been reported to exhibit fast and high response at room temperature and detect $10 \mathrm{ppb}$ $\mathrm{NO}_{2}$ when operated at $165^{\circ} \mathrm{C}$. Although the detection of $10 \mathrm{ppb}$ of nitrogen dioxide is possible at room temperature, the sensor does not recover its baseline resistance when cleaning in dry air at such low temperature [8]. Ueda et al. using VA-CNTs synthesized by thermal CVD as sensing active layer showed that variation in the conductivity was proportional to the concentration of target gas, such as $\mathrm{NO}_{2}$ [9]. However, the low chemical reactivity and selectivity of the pristine CNTs associated to their structure consisting of a hexagonal network of $\mathrm{sp}^{2}$-hybridized $\mathrm{C}$ atoms had prevented their use as sensing layer. Consequently, the functionalization of CNTs has been reported as a good strategy to enhance the sensitivity and the selectivity of the CNT-based sensors [10-12]. The conception of CNT-metal cluster hybrids has been developed as the sensitive material of the device, where the metal cluster surfaces act as reactive sites for the adsorption of the target molecules [13]. This was firstly shown using palladium on individual singlewalled nanotubes in the detection of $\mathrm{H}_{2}$ with a $50 \%$ higher response than the sensor made of pristine carbon nanotubes [14]. Following this report, it was showed that the gas sensitivity of metal $(\mathrm{Au}, \mathrm{Pt})$-functionalized multi-walled nanotubes randomly arranged was significantly improved for $\mathrm{NO}_{2}$ gas detection [15]. Later, VA-CNTs produced by PECVD were functionalized with nominally $5 \mathrm{~nm}$-thick metal nanoparticles by magnetron sputtering, providing a higher sensitivity to $\mathrm{NO}_{2}$ [16]. Based on these reported results, it was shown that the sensitivity of the CNT gas sensor depends on nanocluster size and sensor working temperature [13-17]. Indeed, the nanoscale size of the metal cluster is necessary to maximize the effect of the gas adsorption and so to affect the electron transport in the CNTs by charge transfer. Concerning the nature of metal nanocluster, it has been shown that despite the fact that gold is inert in bulk form, it is catalytically active in the nanometer range [18]. This increased reactivity has been explained by the presence of low-coordinated gold atoms such as the atoms on the corners and edges of particles, particularly abundant on the nanometer-sized particles $[19,20]$. Accordingly, the loading of gold nanoparticles has been reported to strongly influence CNT sensor sensitivity $[17,21,22]$.
In this work we study the influence of the length of aligned CNTs decorated with gold particles in the gas sensing applications. We investigated the sensing response of VA-CNTs with different lengths $(150,300$ and $500 \mu \mathrm{m})$, decorated with gold nanoparticles, to a $\mathrm{NO}_{2}$ atmosphere at room temperature. Moreover, the effect of humidity from dry to $50 \%$ R.H. on the gas sensing was also studied. The morphology of the active layer and its chemical composition was characterized by using scanning and transmission electron microscopies (SEM and TEM), and X-ray photoelectron spectroscopy (XPS), respectively.

\section{Experimental \\ Vertically aligned carbon nanotube growth}

VA-CNT synthesis was carried out in a thermal CVD reactor using $\mathrm{C}_{2} \mathrm{H}_{4}$ as carbon source. $\mathrm{Si}$ wafers with native $\mathrm{SiO}_{2}$ were used as substrates. $\mathrm{Al}_{2} \mathrm{O}_{3}(30 \mathrm{~nm})$ were used as buffer layer on wafer pieces and $\mathrm{Fe}(6 \mathrm{~nm})$ used as active catalyst. The multilayer system composed of $\mathrm{Si} /$ native $\mathrm{SiO}_{2} / \mathrm{Al}_{2} \mathrm{O}_{3} / \mathrm{Fe}$ will be called from now the catalyst. The $\mathrm{Al}_{2} \mathrm{O}_{3}$ and $\mathrm{Fe}$ layers were deposited under $2 \mathrm{mTorr}$ and $20 \mathrm{mTorr}$ pressures using radio frequency (RF) and direct current (DC) magnetron sputtering, respectively. For the CNT growth, the reactor was heated to $750{ }^{\circ} \mathrm{C}$ at atmospheric pressure under Ar flow (120 sccm). The catalyst was placed inside the reactor and the $\mathrm{H}_{2}$ flow $(120 \mathrm{sccm})$ was introduced into the reactor. After $5 \mathrm{~min}$, Ar was replaced by the $\mathrm{C}_{2} \mathrm{H}_{4}$ flow $(50 \mathrm{sccm}$ ). The growth time was varied from 7 to $30 \mathrm{~min}$ for synthesizing VA-CNTs with different lengths $(150,300$ and $500 \mu \mathrm{m})$. After the growth, $\mathrm{H}_{2}$ and $\mathrm{C}_{2} \mathrm{H}_{4}$ were replaced by $\mathrm{Ar}(120 \mathrm{sccm})$. Finally, the sample was taken out from the reactor. The detailed synthesis was reported in [23].

\section{Formation of gold nanoparticles}

Gold nanoparticles were prepared by the physical vapor deposition (PVD) technique. This method is well-known to synthesize nanoparticles based on the aggregation of free atoms generated in the gas phase by DC magnetron sputtering (with a power of $75 \mathrm{~W}$ ) from a gold target under Ar atmosphere (180 mTorr). It allows the production of well-dispersed nanoparticles in the gas phase with a narrow size distribution, production independent of the target substrate. The gold nanoparticles synthesized have a mean diameter of $6 \pm 2 \mathrm{~nm}[24]$.

\section{Material characterization}

The alignment and the length of the VA-CNT samples were investigated using field emission SEM (FE-SEM) on a JEOL $7500 \mathrm{~F}$ microscope. TEM was used to determine the metal cluster size and their localization on the CNTs. For that, a part of the VA-CNTs was removed from the surface and dispersed in ethanol, and a drop of this solution was deposited onto a commercial lacey-carbon grid. The TEM experiments were 
carried out with a FEI Tecnai 10 and a Philips CM200 for higher resolution, operating at 80 and $200 \mathrm{kV}$, respectively. Raman spectroscopy was performed at room temperature with a LabRam Horiba spectrometer with a laser wavelength of $514 \mathrm{~nm}$.

In order to evaluate the chemical composition of the samples' surface, XPS was performed in a VERSAPROBE PHI 5000 from Physical Electronics, equipped with a monochromatic Al $\mathrm{K} \alpha \mathrm{X}$-ray source with a highly focused beam size set at $200 \mu \mathrm{m}$. The energy resolution was $0.7 \mathrm{eV}$. The binding energies were calibrated using the Au $4 f$ peaks.

\section{Sensor preparation}

Parallel silver electrodes, with an electrode gap of $800 \mu \mathrm{m}$, were drop casted on top of the VA-CNTs samples. A commercial Ag paste (Heraeus AD 1688-06) was employed. The electrodes were cured at $170{ }^{\circ} \mathrm{C}$ for $30 \mathrm{~min}$. The backside of the samples was glued with a thermally conductive epoxy to an alumina support which had a screen printed Pt resistor to be used as a heater. Au wires were employed to connect both the electrodes and the heater resistor to a small PCB board that can be plugged into our sensor test chamber.

\section{Measurement set-up}

In a typical measurement cycle, dry air was flowed through the test chamber for at least $30 \mathrm{~min}$ for allowing the sample resistance to stabilize (i.e., a stable baseline is reached). Then a given concentration of nitrogen dioxide was introduced into the test chamber and kept constant for $15 \mathrm{~min}$. This was implemented by mixing the flows of dry air and nitrogen dioxide diluted in dry air. The total flow remained always constant and equal to $100 \mathrm{sccm}$ during the detection of $\mathrm{NO}_{2}$ and cleaning phases. The measurement rig comprises a set of computercontrolled mass flow meters and electro-valves to ensure that reproducible concentrations of the gases are delivered to the test chamber. During detection, the samples were kept at $30{ }^{\circ} \mathrm{C}$. At the cleaning phase, the flow was switched again to dry air and heating was applied to the sample $\left(150^{\circ} \mathrm{C}\right)$ for about $30 \mathrm{~min}$. During the whole process of response and recovery, an AGILENT multimeter was employed to acquire the DC resistance of the sensors. When measurements were performed in the presence of humidity, the flow of $\mathrm{NO}_{2}$ diluted in dry air was humidified using a liquid mass flow system.

\section{Results and Discussion Morphology and structure characterization of gold-decorated VA-CNTs}

Before investigating the sensing response of VA-CNTs decorated with gold nanoparticles to the detection of $\mathrm{NO}_{2}$ gas, the morphology of the active layers and their chemical compos- ition are characterized by using SEM, TEM, and XPS. The FE-SEM images present VA-CNT rugs with different lengths used in the experiments (Figure 1). The length of the CNTs increases linearly with growth time at the beginning and the growth rate decreases after a certain time (depending on the experimental conditions) due to the poisoning of the catalysts [23]. The CNT growths were realized with three different times: 7,15 and $30 \mathrm{~min}$, giving rug lengths of 150,300, and approximately $500 \mu \mathrm{m}$ (Figure 1a, b and c, respectively). The growth rate in the CVD conditions used in this study was estimated to be $17.5 \mu \mathrm{m} / \mathrm{min}$. The last image (Figure 1d) illustrates, for a sample with a rug of about $500 \mu \mathrm{m}$-long tubes, the silver electrode drop casted on top of VA-CNTs.

The SEM images in Figure 2 are shown to exemplify the general morphology of the sensor. The top-view is similar to that of non-aligned CNTs where they seem randomly oriented (Figure 2a). Note that the gold nanoparticles were difficult to observe on top of VA-CNTs due to their diameters. The side view shows the alignment direction of the CNTs, perpendicularly to the substrate surface (Figure 2b).

The high resolution TEM images show the details of the nanotubes aligned inside the forest (Figure 3). The CNTs were found to consist of multi-walled nanotubes with different wall number (the average value was about a dozen walls). Moreover, the nanotubes showed structural defects as exemplified in Figure $3 b$. The presence of defects along the length of the tube is related to the relatively low synthesis temperature used $\left(750{ }^{\circ} \mathrm{C}\right)[25]$. These defects are generally imperfections along the graphitic walls (breaks, dangling bonds due to the presence of $\mathrm{sp}^{3}$ carbon, etc.) and explained the low crystallinity of the CNTs [25].

Raman spectroscopy was used to compare the density of defects for the different samples. Figure 4 shows the typical Raman spectrum recorded on the studied samples. This figure shows the first-order characteristic peaks with a $\mathrm{G}$ band at $1575 \mathrm{~cm}^{-1}$ related to the in-plane oscillations of $\mathrm{sp}^{2}$ carbon atoms due to the graphitic nature of the nanotubes [26] and a D band peak at $1332 \mathrm{~cm}^{-1}$ indicating the presence of defects (carbonaceous impurities, broken $\mathrm{sp}^{2}$ bonds in the sidewalls, etc.) [27]. The intensity ratio $\mathrm{D} / \mathrm{G}$ bands was similar for all samples. The presence of a high intensity D band in the Raman spectrum supports the conclusion drawn from the high resolution TEM images (Figure 3), because its high intensity indicates the low crystallinity of the VA-CNTs.

After characterizing the CNTs, the gold nanoparticles on top of the nanotube forest were investigated using TEM in order to evaluate their distribution at the surface of the CNTs (Figure 5). 


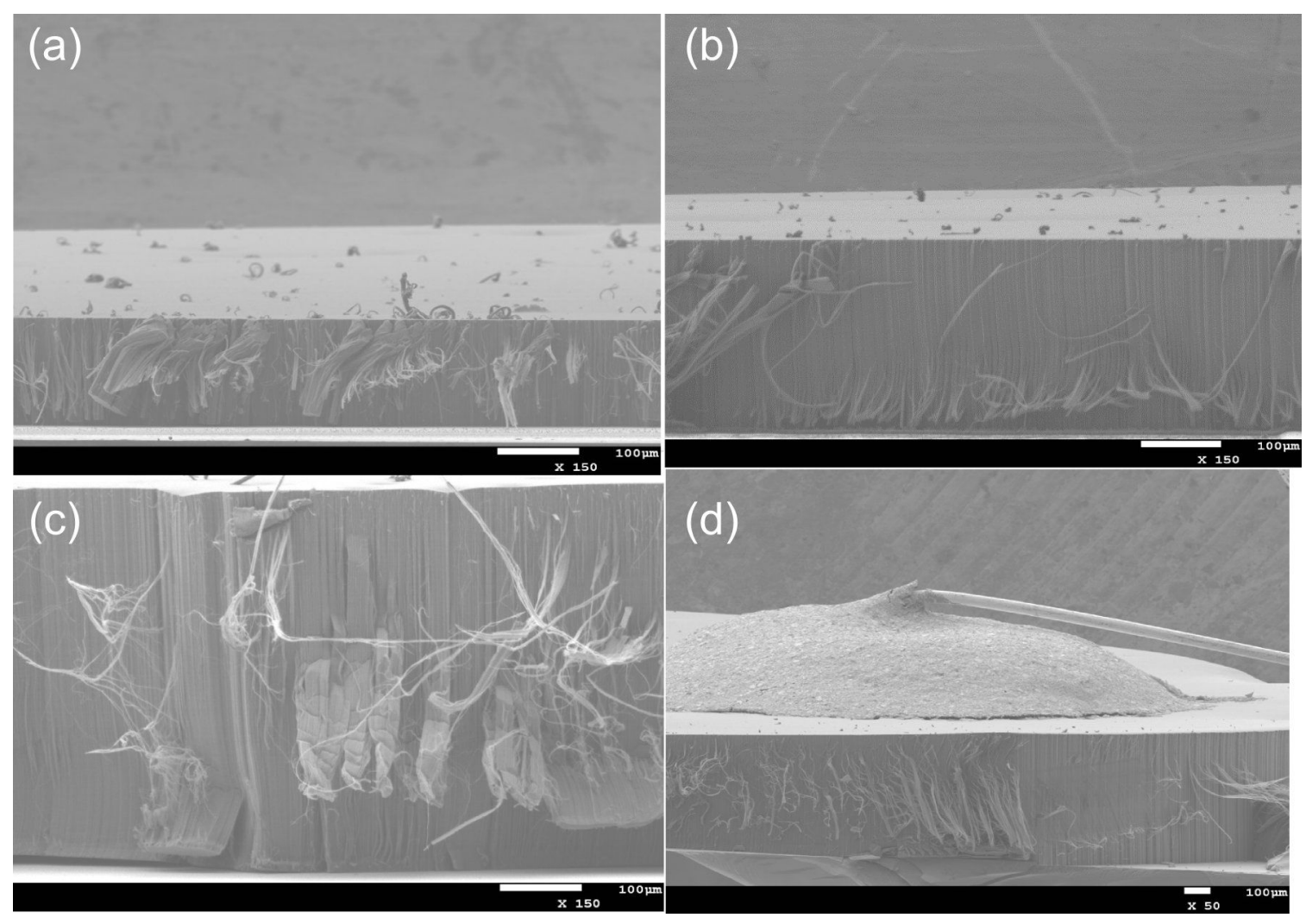

Figure 1: FE-SEM images of sensor devices made of VA-CNTs decorated with gold nanoparticles with different CNT lengths of (a) $150 \mu \mathrm{m}$, (b) $300 \mu \mathrm{m}$, (c) $510 \mu \mathrm{m}$ and (d) image of a silver electrode drop casted on top of the device.
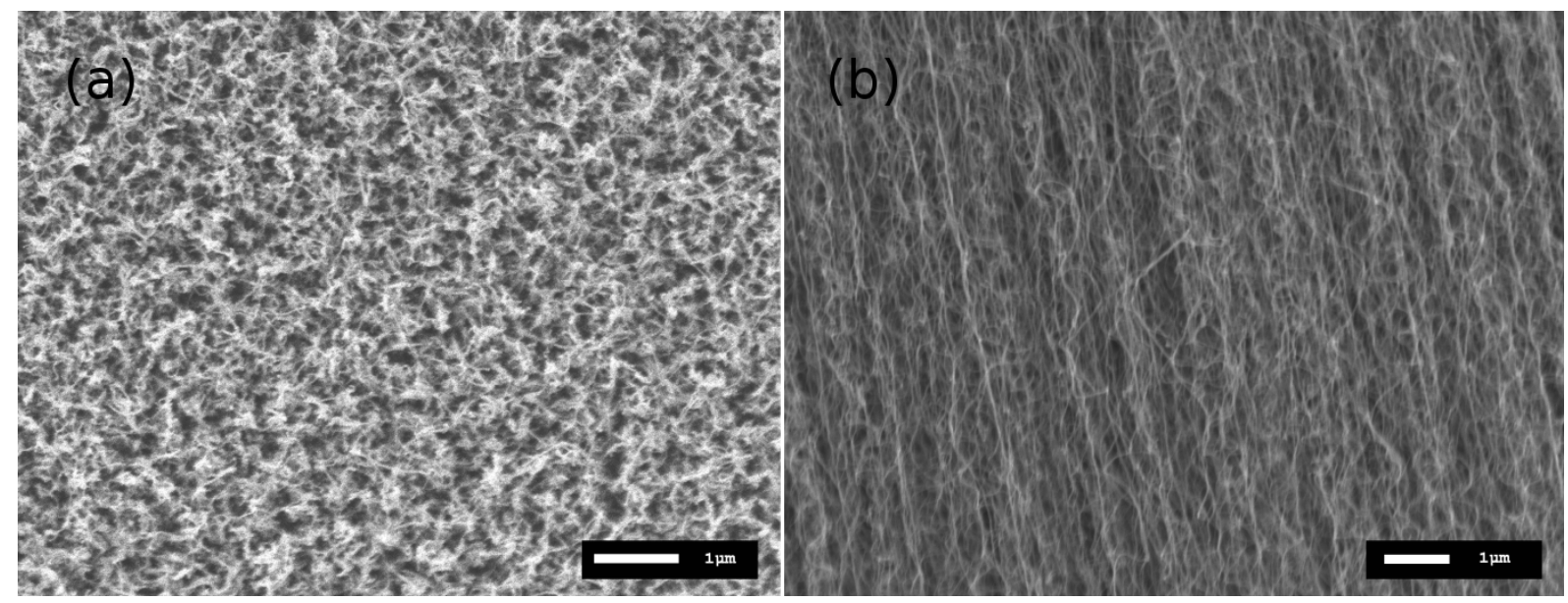

Figure 2: (a) Top and (b) side SEM views of the VA-CNTs.

After the dispersion of the VA-CNTs in ethanol, a drop of the solution was deposited onto a commercial lacey-carbon grid which is well-visible in Figure 5a. Despite the dispersion of CNTs for the characterization, some VA-CNTs are still aggregated as exemplified in Figure 5a. The gold nanoparticles can be observed only at one of the ends of these aggregates (Figure 5b and 5c), meaning that metal is deposited on the top surface of the forest and not along the entire length of the CNTs. This fact is easily explained by the technique used for the decoration of VA-CNTs by gold nanoparticles, i.e., 


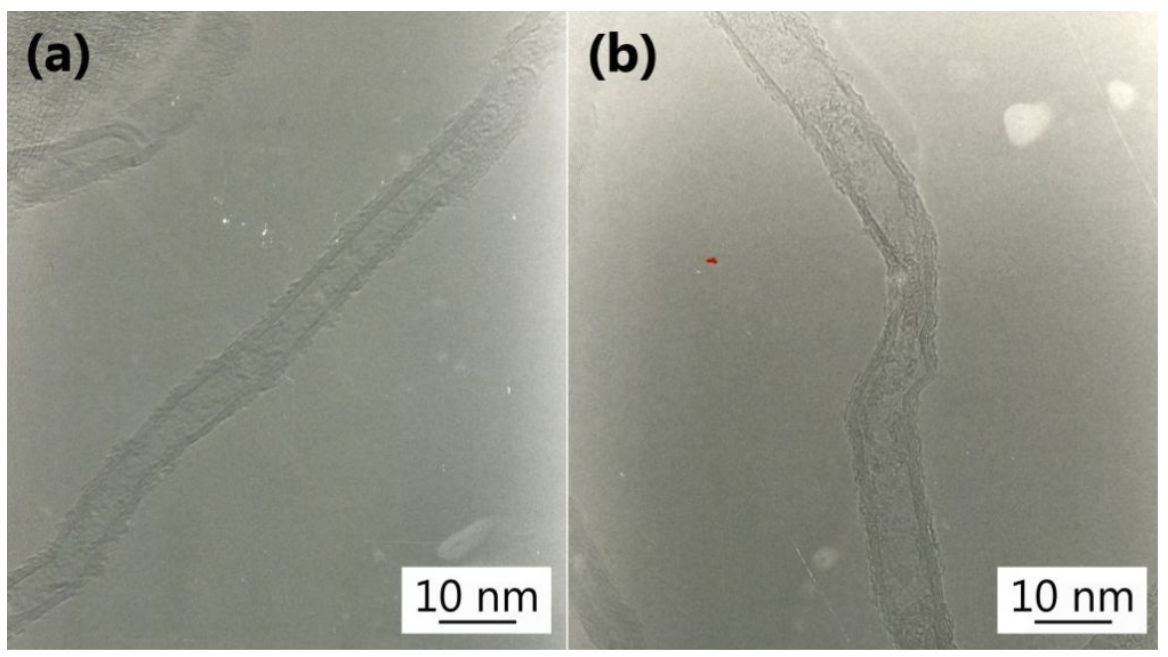

Figure 3: High resolution TEM images of the carbon nanotubes constituting the forests.

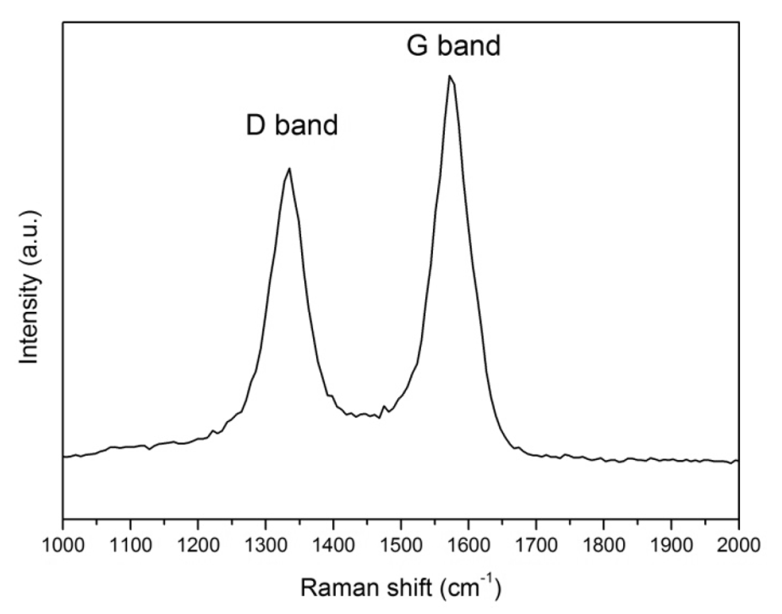

Figure 4: Typical Raman spectrum of VA-CNT sensors. magnetron sputtering, technique well-known for surface functionalization. Based on the TEM images, gold nanoparticles exhibit a spherical shape and a mean diameter of about $6 \mathrm{~nm}$. The size of the nanoparticles was mainly controlled by the duration of the process with the given sputtering parameters.

XPS analyses were performed in order to evaluate if chemical changes were induced on the CNTs after the gold decoration. Figure 6 shows the XPS survey spectra of CNTs before and after the deposition of gold nanoparticles. On both spectra, the peaks at $284.3 \mathrm{eV}$ and at $533.0 \mathrm{eV}$, generated by photoelectrons emitted from the $\mathrm{C} 1 s$ and $\mathrm{O} 1 s$ core levels, respectively, can be observed. The atomic concentration of oxygen at the CNT surface increases from 4.0 to $8.5 \%$ after gold decoration. The presence of oxygen is intrinsic to the CNT CVD synthesis and mainly arises from the oxygen adsorbed on their surface, while its increase after the decoration can be due to the generation of
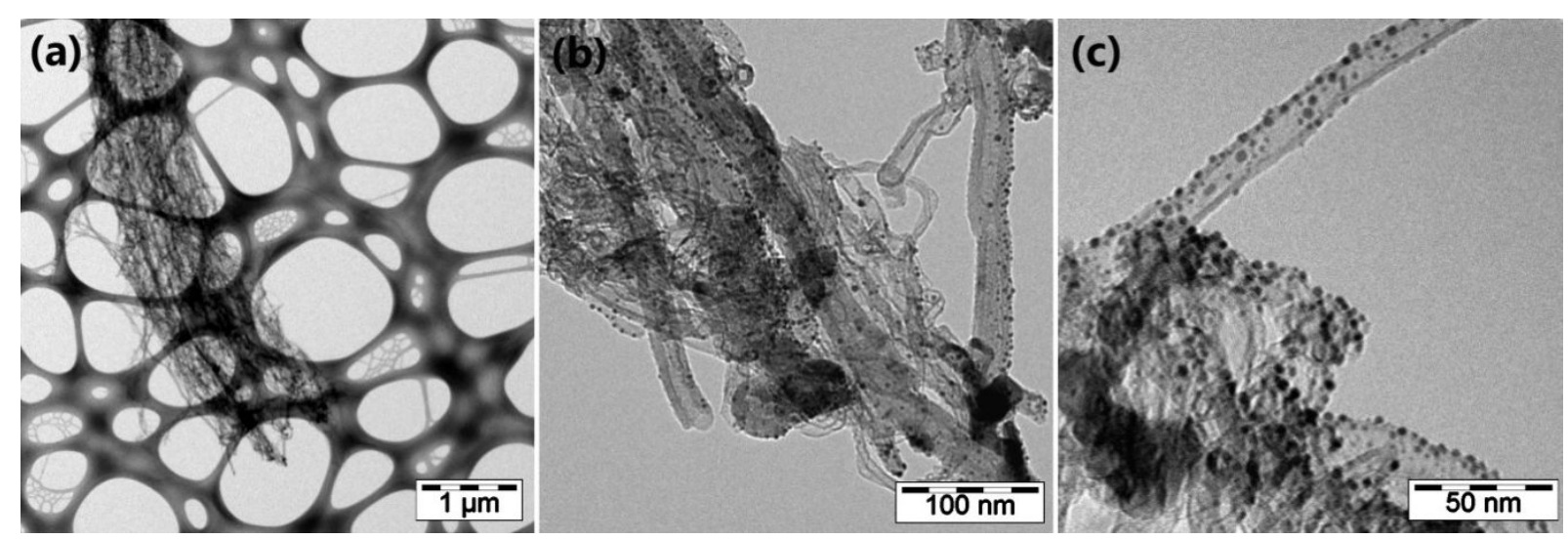

Figure 5: TEM images of VA-CNTs decorated with gold nanoparticles. 


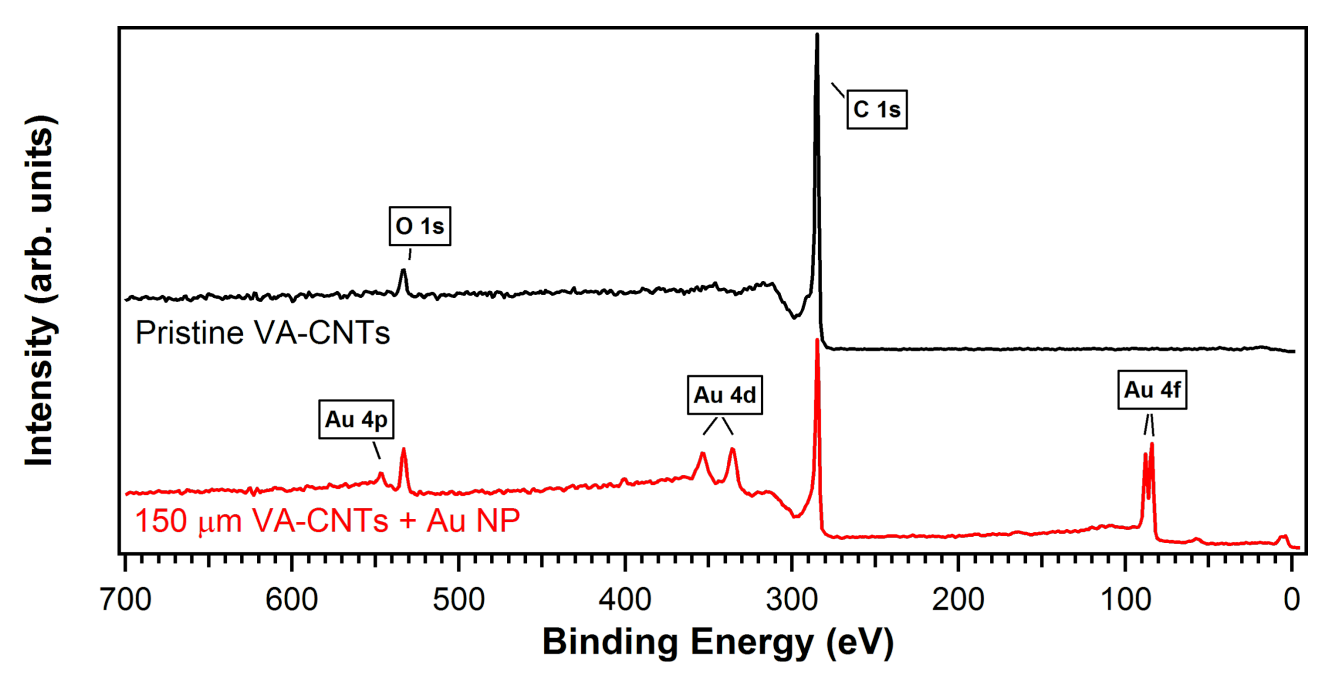

Figure 6: XPS survey spectra for pristine VA-CNTs (top, black line) and $150 \mu$ m-long VA-CNTs decorated with 6 nm-diameter gold nanoparticles on top (bottom, red line).

defects during the gold evaporation. In addition to these peaks, the spectrum recorded after Au evaporation shows additional structures generated by photoelectrons emitted from $\mathrm{Au}$ atoms: the more prominent ones being the $4 f$ doublet components at binding energy of $84.0 \mathrm{eV}\left(4 f_{7 / 2}\right)$ and $87.6 \mathrm{eV}\left(4 f_{5 / 2}\right)$, the $4 d$ doublet at $335.1 \mathrm{eV}\left(4 d_{5 / 2}\right)$ and $353.2 \mathrm{eV}\left(4 d_{3 / 2}\right)$ and the component $4 p_{3 / 2}$ at $546.3 \mathrm{eV}$ of the $4 p$ doublet.

The C $1 s$ core level spectrum is the best monitor of the chemical changes onto the CNTs surface. Figure 7a presents the $\mathrm{C} 1 \mathrm{~s}$ core level recorded on the $150 \mu \mathrm{m}$-long VA-CNTs decorated with $6 \mathrm{~nm}$-diameter gold nanoparticles. A Shirley background has been subtracted. The main peak at $284.3 \mathrm{eV}$ is generated by $\mathrm{sp}^{2}$ hybridized graphitic carbon atoms located on the walls of the CNTs, it is strongly asymmetric and it has been fitted by a Doniach-Sunjic lineshape with an asymmetry parameter $\alpha$ equal to 0.1 . Voigt profiles were used to reproduce the other features observed in the spectrum: the peak at $284.9 \mathrm{eV}$ is associated to photoelectrons emitted from amorphous carbon atoms with $\mathrm{sp}^{3}$ bonds, formed during the CNTs synthesis as also confirmed by the defects imaged by HR-TEM (Figure 3 ) and by the D band measured by Raman (Figure 4); the peak at $290.4 \mathrm{eV}$ corresponds to the electron energy loss peak due to $\pi$-plasmon excitations. These three peaks are characteristics of C $1 s$ core level from CNTs [28]. The additional small peak (relative area of $5 \%$ ) at $286.4 \mathrm{eV}$ is due to the presence of oxygen [29]. The low intensity of the components related to defects and the presence of oxygen indicates that the $\mathrm{sp}^{2}$ structure is preserved.

Figure $7 \mathrm{~b}$ presents the $\mathrm{Au} 4 f$ core level spectrum used as a reference to align the binding energies. It can be fitted by a doublet of Doniach-Sunjic lineshapes with an asymmetric parameter of 0.12 , the core level shift between $4 f_{7 / 2}$ and $4 f_{5 / 2}$ being $3.68 \mathrm{eV}$, in agreement with tabulated values [30].
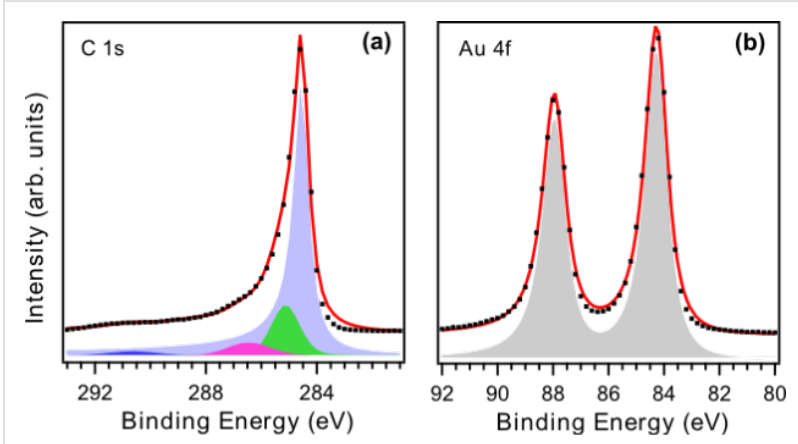

Figure 7: XPS core level spectra of $C 1 s(a)$ and $A u 4 f(b)$ recorded on $150 \mu \mathrm{m}$-long VA-CNTs decorated with $6 \mathrm{~nm}$-diameter gold nanoparticles on top. A Shirley background has been subtracted, experimental data (black dots) and peaks resulting from a least-square fitting procedure (red lines). Fitting peaks of $\mathrm{C} 1 \mathrm{~s}$ (a): light blue for $\mathrm{sp}^{2}$ carbon, green for $\mathrm{sp}^{3}$ amorphous carbon, purple for $\mathrm{C}-\mathrm{O}$ and dark blue for ח-plasmon excitations.

\section{Gas sensing properties}

Sensors based on Au-decorated VA-CNTs with different lengths responded to $\mathrm{NO}_{2}$ at room temperature. However, mild heating at $150{ }^{\circ} \mathrm{C}$ was needed to help desorb the species from the surface so the baseline resistance could be fully recovered. This is not surprising because a rather strong interaction (chemisorption) between oxygen plasma treated or gold nanoparticle decorated CNTs and $\mathrm{NO}_{2}$ has been reported $[22,31]$. Sensor resistance decreased in the presence of $\mathrm{NO}_{2}$ (an oxidizing species), which confirms that the VA-CNT carpets behave as $p$-type semiconductors. 
The response to $\mathrm{NO}_{2}$ depends on the length of the VA-CNTs (Figure 8). The highest response is obtained for sensors employing $300 \mu \mathrm{m}$-long tubes (Table 1). This can be due to the fact that these sensors offer the highest effective surface area (or optimal surface to volume ratio) for interaction with $\mathrm{NO}_{2}$. The fact that VA-CNTs form a very compact forest may make difficult for $\mathrm{NO}_{2}$ to diffuse and adsorb within the entire thickness of the film in the case of $500 \mu \mathrm{m}$-long tubes. Additionally, the chemical sensitization effect of Au nanoparticles sitting on top of the CNT film may be lost beyond a given depth, which would also explain the loss of sensitivity found in $500 \mu \mathrm{m}$-thick films. This result could change if the density of the carbon nanotube forest changed (e.g., lower densities would enable a complete $\mathrm{Au}$ sensitization or a better diffusion of nitrogen dioxide along the entire film).

The pattern of response to nitrogen dioxide remains basically unchanged when the background humidity level is changed from dry to $50 \%$ R.H. However, a general increase in response is observed. These results are in agreement to what was reported by Yao and co-workers [32].

Considering that the active sites are oxygenated defects and $\mathrm{Au}$ nanoparticles, a possible reaction pathway for $\mathrm{NO}_{2}$ on the surface of CNTs when the humidity level is very low is as follows [31,33]:

$$
\begin{gathered}
\mathrm{NO}_{2}(\mathrm{~g})+\text { Oxygenated defect site } \rightarrow \mathrm{NO}_{3}(\mathrm{ad}) \\
\mathrm{NO}_{2}(\mathrm{~g})+\mathrm{Au} \text { site } \rightarrow \mathrm{NO}(\mathrm{g})+\mathrm{Au}-\mathrm{O} \\
\mathrm{NO}_{2}(\mathrm{~g})+\mathrm{Au}-\mathrm{O} \rightarrow \mathrm{Au}-\mathrm{NO}_{3}(\mathrm{ad})
\end{gathered}
$$

At an intermediate humidity level such as the one tested here (i.e., $50 \%$ R.H.), an additional reaction pathway is [34]:

$$
\begin{gathered}
3 \mathrm{NO}_{2}(\mathrm{~g})+\mathrm{H}_{2} \mathrm{O} \rightarrow \mathrm{NO}(\mathrm{g})+2 \mathrm{HNO}_{3} \\
2 \mathrm{NO}_{2}(\mathrm{~g})+2 \mathrm{NO}(\mathrm{g}) \rightarrow 2 \mathrm{NO}_{3}(\mathrm{ad})+\mathrm{N}_{2}(\mathrm{~g})
\end{gathered}
$$

At very low humidity levels, since the amount in weight $\%$ of catalyst loading is small, the generation of $\mathrm{NO}_{3}$ will remain low and $\mathrm{NO}_{2}$ will be the dominating species. However, at higher humidity levels, the $\mathrm{HNO}_{3}$ produced according to reaction (4) will form $\mathrm{C}=\mathrm{O}$ bonds on the surface of CNTs, which will enhance reaction (1). Additionally, reaction (4) also enables reaction (5). As a result, $\mathrm{NO}_{3}$ will become the dominating species in the presence of humidity and the overall response is increased [31].

\section{Conclusion}

We have shown that low temperature CVD grown vertical aligned CNTs can be used as active layer for gas sensing. The

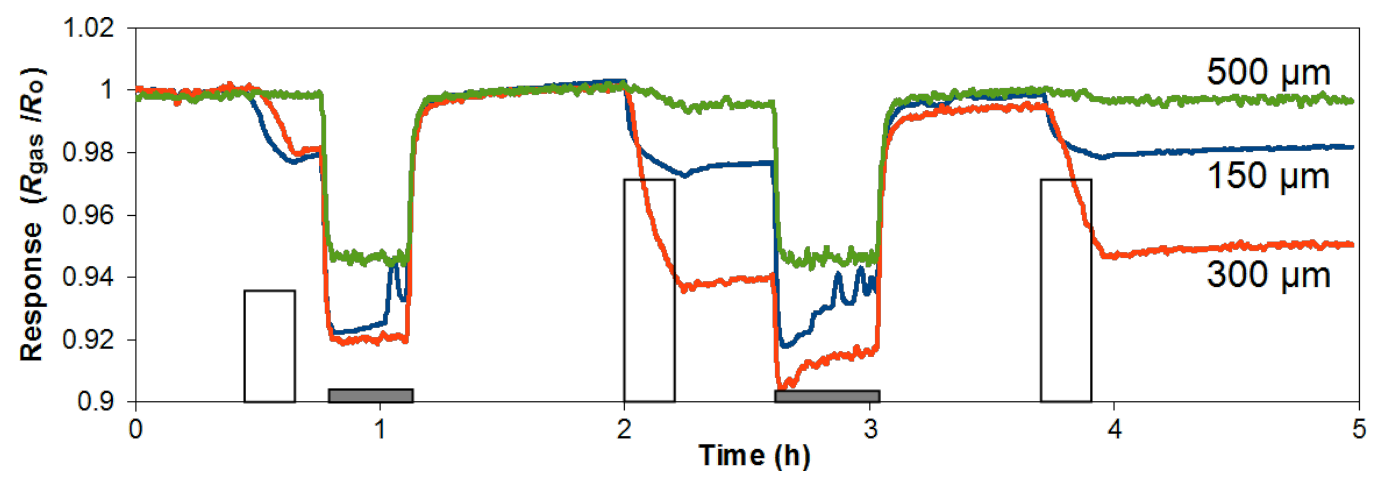

\begin{tabular}{|c|c|c|c|c|}
\hline \multirow[b]{2}{*}{ Length $(\mu \mathrm{m})$} & \multicolumn{4}{|c|}{ Relative resistance change to $\mathrm{NO}_{2} \Delta R / R_{0}(\%)$} \\
\hline & 0.5 ppm @ dry air & 1 ppm @ dry air & 0.5 ppm @ 50\% R.H. & 1 ppm @ 50\% R.H. \\
\hline 150 & 2.2 & 2.8 & 3.5 & 5 \\
\hline 300 & 2 & 6.2 & 4 & 7.5 \\
\hline 500 & - & $<0.5$ & 2 & 4 \\
\hline
\end{tabular}

Figure 8: Room temperature detection of $\mathrm{NO}_{2}$ for sensors with different CNT lengths. White pulses indicate the exposure to $0.5 \mathrm{ppm}, 1 \mathrm{ppm}$ and $1 \mathrm{ppm}$ of nitrogen dioxide (duration was $15 \mathrm{~min}$ ). Grey bars indicate the periods of heating at $150{ }^{\circ} \mathrm{C}$ that help clean the surface of CNT after being exposed to nitrogen dioxide. Heating is not applied after the last exposure cycle and baseline is not regained.

Table 1: Relative resistance change to $\mathrm{NO}_{2}$ depending on the humidity level. 
characterization of the VA-CNTs samples showed that the low temperature growth lead to the formation of defects at the CNT surface however the perfect vertical alignment was obtained. The deposition of gold particles by PVD restricts the formation particles at the sample surface (region near the tips), a slight increase in the oxygen content after the gold deposition was associated with formation of defects.

The CNT length was found to play an important role in the sensitivity for detecting nitrogen dioxide at room temperature when films of VA-CNTs decorated with gold nanoparticles of $6 \mathrm{~nm}$ diameter are used as sensors. The sensing test showed that an 'optimal' length of $300 \mu \mathrm{m}$ for the VA-CNTs maximizes the response towards $\mathrm{NO}_{2}$. This fact is explained by the highest effective surface area obtained with $300 \mu \mathrm{m}$ CNT length for interaction with $\mathrm{NO}_{2}$. Upon studying the influence of humidity level from dry to $50 \%$ R.H., a global increase in the sensing response was observed for all the sensors regardless of their lengths.

\section{Acknowledgements}

This work is financially supported by the Belgian Fund for Scientific Research (FSR-FNRS) under FRFC contract "Chemographene', (No. 2.4577.11), by the Directorate of Research in Wallonia, under the scope of the ERA-NET MATERA programme and by COST Action MP0901. J.-F. Colomer is a Research Associate of the National Funds for Scientific Research (FNRS, Belgium). The authors thank B. Hackens for the Raman measurements. This research used resources of the Electron Microscopy Service located at the University of Namur ("Plateforme Technologique Morphologie - Imagerie"). E. Llobet is supported by the ICREA Academia Award.

\section{References}

1. Jiménez-Cadena, G.; Riu, J.; Rius, F. X. Analyst 2007, 132, 1083-1099. doi:10.1039/b704562j

2. Zhang, W.-D.; Zhang, W.-H. J. Sensors 2009, 2009, No. 160698. doi:10.1155/2009/160698

3. Goldoni, A.; Petaccia, L.; Lizzit, S.; Larciprete, R. J. Phys.: Condens. Matter 2010, 22, 013001. doi:10.1088/0953-8984/22/1/013001

4. Sayago, I.; Santos, H.; Horrillo, M. C.; Aleixandre, M.; Fernández, M. J.; Terrado, E.; Tacchini, I.; Aroz, R.; Maser, W. K.; Benito, A. M.; Martínez, M. T.; Gutiérrez, J.; Muñoz, E. Talanta 2008, 77, 758-764. doi:10.1016/j.talanta.2008.07.025

5. Kong, J.; Franklin, N. R.; Zhou, C.; Chapline, M. G.; Peng, S.; Cho, K.; Dai, H. Science 2000, 287, 622-625. doi:10.1126/science.287.5453.622

6. Lu, Y.; Partridge, C.; Meyyappan, M.; Li, J. J. Electroanal. Chem. 2006, 593, 105-110. doi:10.1016/j.jelechem.2006.03.056

7. Jang, Y.-T.; Moon, S.-I.; Ahn, J.-H.; Lee, Y.-H.; Ju, B.-K. Sens. Actuators, B 2004, 99, 118-122. doi:10.1016/j.snb.2003.11.004
8. Valentini, L.; Cantalini, C.; Armentano, I.; Kenny, J. M.; Lozzi, L.; Santucci, S. Diamond Relat. Mater. 2004, 13, 1301-1305. doi:10.1016/j.diamond.2003.11.011

9. Ueda, T.; Bhuiyan, M. M. H.; Norimatsu, H.; Katsuki, S.; Ikegami, T.; Mitsugi, F. Physica E 2008, 40, 2272-2277. doi:10.1016/j.physe.2007.12.006

10. Van Hooijdonk, E.; Bittencourt, C.; Snyders, R.; Colomer, J.-F. Beilstein J. Nanotechnol. 2013, 4, 129-152. doi:10.3762/bjnano.4.14

11. Bittencourt, C.; Navio, C.; Nicolay, A.; Ruelle, B.; Godfroid, T.; Snyders, R.; Colomer, J.-F.; Lagos, M. J.; Ke, X.; Van Tendeloo, G.; Suarez-Martinez, I.; Ewels, C. P. J. Phys. Chem. C 2011, 115, 20412-20418. doi:10.1021/jp2057699

12. Saikia, N. J.; Ewels, C.; Colomer, J.-F.; Aleman, B.; Amati, M.; Gregoratti, L.; Hemberg, A.; Thiry, D.; Snyders, R.; Bittencourt, C. J. Phys. Chem. C 2013, 117, 14635-14641. doi:10.1021/jp404177p

13. Zhao, Q.; Nardelli, M. B.; Lu, W.; Bernholc, J. Nano Lett. 2005, 5, 847-851. doi:10.1021/nl050167w

14. Kong, J.; Chapline, M. G.; Dai, H. Adv. Mater. 2001, 13, 1386-1389. doi:10.1002/1521-4095(200109)13:18<1384::AID-ADMA1384>3.0.CO; 2-8

15. Penza, M.; Cassano, G.; Rossi, R.; Alvisi, M.; Rizzo, A.; Signore, M. A.; Dikonimos, Th.; Serra, E.; Giorgi, R. Appl. Phys. Lett. 2007, 90, 173123. doi:10.1063/1.2722207

16. Penza, M.; Rossi, R.; Alvisi, M.; Signore, M. A.; Cassano, G.; Dimaio, D.; Pentassuglia, R.; Piscopiello, E.; Serra, E.; Falconieri, M. Thin Solid Films 2009, 517, 6211-6216. doi:10.1016/j.tsf.2009.04.009

17. Penza, M.; Rossi, R.; Alvisi, M.; Cassano, G.; Signore, M. A.; Serra, E.; Giorgi, R. Sens. Actuators, B 2008, 135, 289-297. doi:10.1016/j.snb.2008.08.024

18. Haruta, M.; Yamada, N.; Kobayashi, T.; lijima, S. J. Catal. 1989, 115, 301-309. doi:10.1016/0021-9517(89)90034-1

19. Barmparis, G. D.; Remediakis, I. N. Phys. Rev. B 2012, 86, 085457. doi:10.1103/PhysRevB.86.085457

20. Hvolbæk, B.; Janssens, T. V. W.; Clausen, B. S.; Falsig, H.; Christensen, C. H.; Nørskov, J. K. Nano Today 2007, 2, 14-18. doi:10.1016/S1748-0132(07)70113-5

21. Penza, M.; Rossi, R.; Alvisi, M.; Cassano, G.; Serra, E. Sens. Actuators, B 2009, 140, 176-184. doi:10.1016/j.snb.2009.04.008

22. Ionescu, R.; Espinosa, E. H.; Sotter, E.; Llobet, E.; Vilanova, X.; Correig, X.; Felten, A.; Bittencourt, C.; Van Lier, G.; Charlier, J.-C.; Pireaux, J. J. Sens. Actuators, B 2006, 113, 36-46. doi:10.1016/j.snb.2005.02.020

23. Colomer, J.-F.; Ruelle, B.; Moreau, N.; Lucas, S.; Snyders, R.; Godfroid, T.; Navio, C.; Bittencourt, C. Surf. Coat. Technol. 2011, 205, S592-S596. doi:10.1016/j.surfcoat.2011.03.040

24. Moreau, N.; Michiels, C.; Masereel, B.; Feron, O.; Gallez, B.; Vander Borght, T.; Lucas, S. Plasma Processes Polym. 2009, 6, S888-S892. doi:10.1002/ppap.200932210

25. Lee, C. J.; Park, J.; Huh, Y.; Yong Lee, J. Chem. Phys. Lett. 2001, 343, 33-38. doi:10.1016/S0009-2614(01)00680-7

26. Eklund, P. C.; Holden, J. M.; Jishi, R. A. Carbon 1995, 33, 959-972. doi:10.1016/0008-6223(95)00035-C

27. Dresselhaus, M. S.; Eklund, P. C. Adv. Phys. 2000, 49, 705-814. doi:10.1080/000187300413184

28. Scardamaglia, M.; Amati, M.; Llorente, B.; Mudimela, P.; Colomer, J.-F.; Ghijsen, J.; Ewels, C.; Snyders, R.; Gregoratti, L.; Bittencourt, C. Carbon 2014, in press. doi:10.1016/j.carbon.2014.05.035 
29. Okpalugo, T. I. T.; Papakonstantinou, P.; Murphy, H.; McLaughlin, J.; Brown, N. M. D. Carbon 2005, 43, 153-161.

doi:10.1016/j.carbon.2004.08.033

30. Hüfner, S. Photoelectron Spectroscopy: Principles and Applications; Springer Verlag: Berlin, Germany, 2003.

doi:10.1007/978-3-662-09280-4

31. Zanolli, Z.; Leghrib, R.; Felten, A.; Pireaux, J.-J.; Llobet, E.; Charlier, J.-C. ACS Nano 2011, 5, 4592-4599. doi:10.1021/nn200294h

32. Yao, F.; Duong, D. L.; Lim, S. C.; Yang, S. B.; Hwang, H. R.; Yu, W. J.; Lee, I. H.; Güneş, F.; Lee, Y. H. J. Mater. Chem. 2011, 21, 4502-4508. doi:10.1039/c0jm03227a

33. Rodriguez, J. A.; Jirsak, T.; Sambasivan, S.; Fischer, D.; Maiti, A. J. Chem. Phys. 2000, 112, 9929-9939. doi:10.1063/1.481629

34. Peng, S.; Cho, K.; Qi, P.; Dai, H. Chem. Phys. Lett. 2004, 387, 271-276. doi:10.1016/j.cplett.2004.02.026

\section{License and Terms}

This is an Open Access article under the terms of the Creative Commons Attribution License

(http://creativecommons.org/licenses/by/2.0), which permits unrestricted use, distribution, and reproduction in any medium, provided the original work is properly cited.

The license is subject to the Beilstein Journal of

Nanotechnology terms and conditions:

(http://www.beilstein-journals.org/bjnano)

The definitive version of this article is the electronic one which can be found at: doi:10.3762/bjnano.5.104 